\title{
Material Entanglements of Writing Practices in the Bronze Age Aegean and Cyprus
}

\author{
Philippa M. Steele ${ }^{1,2}$ \\ 1 Faculty of Classics, University of Cambridge, Cambridge CB3 9DA, UK; pms45@cam.ac.uk \\ 2 Magdalene College, University of Cambridge, Cambridge CB3 OAG, UK
}

Received: 31 July 2020; Accepted: 18 December 2020; Published: 21 December 2020

\begin{abstract}
The present paper explores theoretical aspects of the study of writing systems and practices. It approaches the mesh that constitutes writing practice through one type of agent: the writing instrument used to write clay documents in the Bronze Age Aegean and Cyprus. On the one hand, this investigation will use types of writing implements and their distribution to think through wider issues concerning the development of writing practices across the Bronze Age Aegean and Cyprus. On the other, it will attempt to establish the place of writing implements within a broader conceptual framework of the people, things and actions that constitute writing practices in this area and period.
\end{abstract}

Keywords: writing; palaeography; stylus; clay; practice; materiality

\section{Introduction}

Writing is a phenomenon that, from a linguistic perspective, is frequently studied in terms of its function of language encoding, an approach very deeply embedded in much literature on writing systems. To speak of writing as existing in systems is itself a product of longstanding structuralist traditions that tend to view writing in a way that abstracts it from the people doing it and the settings in which it is being done. More recent research on writing as a practice and especially on the materiality of written objects has thankfully made a very significant contribution to redressing the balance and placing a focus on physical, social and technological contexts of writing (the traction gained by such approaches can be easily seen in a number of recent volumes on material approaches e.g., [1-3] and social context and agency e.g., [4,5], amidst a growing body of literature). While these growing trends have greatly improved our understanding of the phenomenon of writing from different perspectives, there remains considerable scope in my view for the linguistic/structuralist and the material/contextualist approaches to be brought into more constructive conversation with each other (some of these issues are discussed more extensively in [6]). In concentrating on the syllabic systems of the Bronze Age Aegean and Cyprus, I will in some senses be preaching to the converted, because the field of Aegean scripts studies (i.e., the study of these systems and the documents written in them) has already been blessed with decades of research that fruitfully brings together linguistic and archaeological approaches and that in many cases pushes the boundaries of interdisciplinarity and results in impressively joined up thinking. However, I hope this paper may add some new perspectives on the ways in which the material and practice-based aspects of writing can be further probed to ask some fruitful questions of the nature and development of writing in these areas and periods.

The approach followed in this paper views materiality not as a static property of an object but as a dynamic one that must also be considered in relation to practice. Kathryn Piquette and Ruth Whitehouse in the introduction to their volume on the materiality of writing ([3] p. 4) notably advocated this wider view: "'Materiality' can thus refer in a general way to the material aspects of artefacts, while also, and importantly, prompting their situation in relation to mutually-informing sets of practices. This enables material to be described as more than a mere 'support' for writing. 
It becomes active in the construction of meanings, from the preliminary work of manufacturing artefact 'blanks' on which marks are made, and the techniques of surface transformation which give rise to written marks, to the ways in which these physical objects were incorporated into subsequent activities, from reading/viewing (where intended) and display, to discard, deposition or loss." From this perspective, objects and materials can be understood as agents in the social setting in which they exist, and in which they play a dynamic role in the interaction between humans and their material surroundings (see also Knappett [7] on such broader approaches to materiality). Practice represents the coalescence of these different aspects and interactions.

The title of this paper introduces the term 'material entanglements', with intentional allusion to the idea of webs of human-thing entanglements (e.g., Hodder [8]) that affect perceptions of the role and agency of things that exist in human society. Such things have material properties that determine and are determined by their interactions with people, and in turn those interactions have social context-making it useful also to introduce anthropological approaches to practice, such as those grounded in Bordieu's concept of 'habitus' (e.g., [9]). In other words, anything that people have or that people do cannot be simple or isolated, and can be understood from multiple angles in relation to the wider mesh of agents, things and practices that make up a given social setting. We can move from the abstract towards more concrete applications with an example. James Whitley's recent discussion of writing in Archaic Greece ([10]) showed one particular way in which the concept of material entanglement can be useful to a study of writing practices. He argued that, in different areas of Archaic Greece, writing and written objects were entangled with other forms of cultural and oral practice to different degrees, and that the nature of writing practices could correspondingly vary. In central Greece in this period, writing seems to be heavily entangled with other forms of cultural expression, including narrative and visual culture (which is obvious, for example, in the frequent appearance of writing on highly decorated and narrative ceramic wares, objects strongly associated with symposiastic activity and elite practice), as well as with sanctuary-based religious practice and with practices related to craft production. In the same period, writing on the island of Crete seems to be far less entangled with these particular areas of social practice and is less visible in e.g., 'private' documents like graffiti and oggetti parlanti (objects that 'speak' to the reader in the first person), while predominant uses of writing are far more impersonal, in particular the monumental legal codes for which Crete is perhaps most famous. The different settings and practices with which writing is entangled in each area are connected with local differences in the nature of writing.

Such entanglements can of course be unpicked further. What do mean when we say that one thing or practice is entangled with another? In the case of a vase with a narrative scene that integrates writing (e.g., the names of figures, direct speech, the signature of the artist), it is abundantly clear that the act of writing was in no sense separate from the act of decorating the vase and painting the figures and scenery that appear on it. It was done by the same person, using the same implements and materials. The placement of the writing depended on and/or dictated the arrangement of pictorial elements. This necessitated technical skill, both in working with the materials, paints and implements and in executing the letters and shapes. The content of the writing required the artist to understand the myth or scene they were depicting, and to have some degree of literacy however limited. The finished vase with its inscription will then become part of a social landscape in which it co-exists and interacts with other objects, many of which will not bear inscriptions but may nevertheless have a meaningful relationship with it. In order to understand a given object, there is a whole mesh of relevant interconnected relationships between humans, materials, objects, practices and social context that need to be explored. For the Bronze Age Aegean, some impressive work has already been done to explore and establish the relationship between the material aspects of writing and the broader context in which inscribed objects are viewed and imbued with meaning (e.g., Flouda [11,12]).

In the context of his ongoing work on cognitive approaches to materiality and material engagement (e.g., [13,14]), Lambros Malafouris has specifically sought to situate Bronze Age Aegean writing practices within a new interpretive framework. This views the production of Linear B tablets as 'a temporally 
unfolding process, or sequence of related processes, encompassing both interaction between humans, situated tool use, and intelligent use of space, bodies and things' (Malafouris [15] p. 75). Crucially, the properties of Linear B as a system are a hybrid to which both the people and the things involved contribute: "the cognitive and the social are inseparable often to such an extent that from the perspective of distributed cognition one may see the social organization of the Linear B system as a form of cognitive architecture in itself" ([15] p. 81, emphasis original). This view is a departure from structuralist linguistic approaches to writing systems in that it sees material and social context of writing as a practice as vital parts of that cognitive architecture, rather than separating the abstract concept of writing as a system from the embodied performance of writing as a practice. We can build on this model by drawing language encoding and writing system structure into the wider mesh of entanglements that encompass but also go beyond the material and social aspects of writing practice. Such combined approaches to cuneiform writing have indeed proven helpful in understanding the development of writing as both system and practice (Overmann [16,17]).

The final theoretical point to make is that by combining different approaches, we may be able to envisage a far wider set of complex connections that coalesce in the practice of writing, including: the concept of representing sound and language in a visible and tangible medium along with the structure of the writing system (including the signs and their shapes and values); the need and potential uses for writing in a given social setting, the types of objects that will bear the writing along with the types of tools used to execute the writing and their material properties; the availability of materials to fashion the objects and tools alongside considerations of their suitability to the intended purpose; the social mechanisms by which individuals learn the conventions of using the writing system and participating in the writing practice; the social contexts in which writing co-exists with other practices and in which writing constitutes a meaningful act. Any attempt to boil down such a practice will necessarily be reductive, and this list of examples is intended to be illustrative rather than exhaustive, and to open up the range of factors that need to be brought into consideration. Within such a mesh of entanglements, we have to envisage the people and objects involved as active agents contributing to the practice of writing.

The present paper is going to approach the mesh that constitutes writing practice through one type of agent, the writing instrument, with a further restriction (in order to cover a manageable range of examples in a meaningful way) that the focus will be on the implements used to write clay documents in the Bronze Age Aegean and Cyprus. On the one hand, this investigation will use types of writing implements and their distribution to think through wider issues concerning the development of writing practices across the Bronze Age Aegean and Cyprus. On the other, it will attempt to establish the place of writing implements within a broader conceptual framework of the people, things and actions that constitute writing practices in this area and period. I intend the main focus to lie in the methodological approach to the material, in order to lay some theoretical groundwork for future study that will, I hope, give scope to engage in far more detail with the material evidence treated (inevitably) only briefly here.

\section{Cherchez Le Stylet}

Across the linear scripts of the Bronze Age Aegean and Cyprus, writing was done in multiple different contexts and using different materials - the seal stones with Cretan Hieroglyphic inscriptions would have been made in a very different way from the stone libation vessels inscribed in Linear A, or the stirrup jars with painted Linear B inscriptions, or the Cypro-Minoan inscribed bronze bowls, to take a few examples from what are usually considered to be separate writing traditions. Each type of inscribed object involved different materials and implements, and different kinds of expertise and specialist craft equipment (which, in a craft context, also raises the question of whether the same implements that were used to add details or decoration to inscribed objects were also used to write on them, and whether this was done by the same person). What all four of the above writing traditions have in common, however, is that they were also often written on clay documents in (exclusively or largely?) administrative contexts that sometimes differ quite considerably from one tradition to another 
('traditions' rather than 'systems' to imply that we are dealing with whole packages of writing practices and their sociocultural context, with which the writing systems are themselves closely bound up; we should also be careful to avoid the assumption that each writing system is exclusively associated with a completely separate tradition - in the case of Cretan Hieroglyphic, Linear A and fledgling Linear B bureaucratic methods, for example, we should certainly be aware of shared features that suggest more complex relationships, on which see Petrakis [18] and Tomas [19]). There is a functional difference here too, because unlike most of the other objects, the clay documents exist primarily to be written on-that is, they are aetiologically connected with the concept and practice of writing and particularly with its bureaucratic functions. For these reasons, the present study is restricted to writing on clay. There is of course far more to be said about writing practices on media other than clay across the Bronze Age Aegean and Cyprus, and ideally we would want to consider writing on other media alongside writing on clay for further comparison, but this lies beyond the possible scope of the present paper. The use of clay documents in all four traditions provides some opportunity to compare them with each other as well as to trace the relations between them, on this occasion placing the implement of writing centre-stage.

Although the study of the Aegean linear scripts is a mature and well populated discipline, which has over the years reached an advanced view of the palaeographic and pinacological features of the documents written in them (particularly in the case of Linear B; see Palaima [20] for an overview), there has been relatively limited direct interest in the implements that were used to write on these documents. In part, that may be because we have very little direct evidence for writing implements in the Bronze Age Aegean and Cyprus. We are certainly also lacking in the kinds of iconographic evidence for styli in areas where cuneiform was used. But even for cuneiform, we find that most evidence is indirect in nature: aside from a few surviving examples, the size, shape and material properties of the stylus (in Mesopotamia such tools were often cut from a reed and unlikely to survive in the archaeological record, although the use of other materials such as bronze is also known) largely have to be reconstructed from the impressions it left on inscribed clay documents (Cammarosano [21]). As we will see, such a methodology will prove to be apposite in the present case study too.

For the Middle Minoan period and the earlier part of the Late Minoan period on Crete (i.e., when Cretan Hieroglyphic and Linear A were in use), no obvious candidate for a stylus survives. For the Mycenaean period, a few small tools of different materials have been identified as potential styli, largely from the northern and eastern areas of the Mycenaean world: from the Argolid, four bone examples and one possibly in bronze from Tiryns as well as a bone example from Mycenae (see Godart [22]), and from Thebes another bone example found in the vicinity of inscribed clay nodules (Olivier, Melena and Piteros [23]); a pointed bronze tool from a cremation at the Khania near Mycenae (Palaiologou [24]) seems to be a doubtful example. However, no styli have survived from Knossos or Pylos, the two sites responsible for the majority of extant Linear B documents. In Bronze Age Cyprus, if we discount the bone tools once identified as styli but now conclusively reinterpreted as weaving tools (Smith [25]), our only likely examples of styli are pointed bronze implements from several sites, although there is a considerable possibility that these objects were used to write on wax tablets rather than clay documents (Pappasavvas [26]). The physical and material features of these styli are considered in more detail below.

The bone implements from the Argolid and from Thebes have a distinctive shape with a tapered blade at one end, coming to a rounded point (see Figure 1). The rest of the object is round in its cross-section, and tapers to a point at the other end. The examples range in length from c.6 to c. $12 \mathrm{~cm}$. The possible bronze example from Tiryns has a blade similar in shape at the end, though the whole implement is thinner and flatter than the bone examples. Louis Godart already showed by experimentation that this shape of stylus could be used successfully to inscribe Linear B tablets ([22] pp. 248-250). 

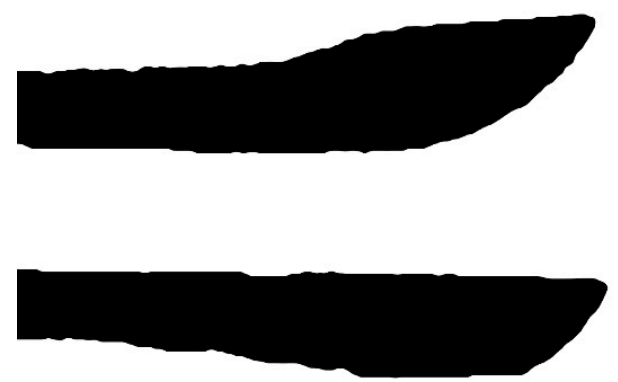

Figure 1. Section of the ends of two bladed bone styli from Tiryns. Drawn by the author after Godart ([22] p. 248 Figure 3).

While the evidence for Mycenaean Greece can be plausibly and confidently linked with writing on clay, which as far as we know was the principal means of recording information in the palatial administrations, the same cannot be said of Cyprus. The bronze implements found at sites including Enkomi and Kalavassos-Agios Dimitrios are pencil-like objects that feature short, sharp points at one end and end in a chisel-like shape at the other. In other words, they look very similar to the sorts of styli that are so well attested in the Roman world, and which were designed for use with wooden tablets coated in wax: the pointed end was used to make the inscription, and the chisel end to scrape the wax for corrections or re-inscription. George Pappasavvas has indeed interpreted them as evidence of the prevalent use of wooden writing boards in Bronze Age Cyprus, which in turn could explain the relatively very small numbers of clay documents that have been found (Pappasavvas [26]). Crucially for our purposes here, these implements are the wrong shape to have produced the surviving Cypriot inscriptions on clay, many of which feature distinctive 'teardrop' shape impressions, although the methods of producing the inscriptions clearly varies (see Steele and Boyes [27]). (see Figure 2).

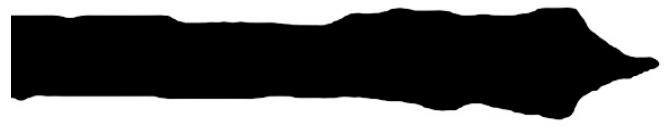

Figure 2. Section of the end of a pointed bronze stylus from Enkomi. Drawn by the author after Pappasavvas ([26] p. 81, Figure 3).

The direct evidence for styli is obviously deficient in several respects. There are long periods of time and wide geographical areas for which surviving examples are missing altogether. The interpretation of the few surviving implements as styli is often tentative, and only the examples from Thebes have a strong contextual motivation for this assumption. It also hardly needs stating that there could have been styli made from perishable materials that could not be expected to be represented in the archaeological record. The evidence is too patchy to determine the degree to which stylus type and usage may have varied in different times and places (or even within any given time or place), which means that the burden of this investigation will fall on the indirect evidence.

\section{Impressions of the Stylus}

The existence and nature of the stylus is heavily dependent on its interactions with people, objects and materials that coalesce to make up writing practice. The material from which a stylus was made was chosen deliberately: it had to be possible to fashion it into the appropriate shape to produce signs of the necessary writing system in the chosen medium (in this case clay), and it had to be durable enough to maintain this shape during prolonged usage, and of the appropriate size to be held and manipulated in the hand. The relationship would never had been entirely straightforward: any given material may have offered both advantages and disadvantages, and the choice of one material over another may have necessitated a compromise between availability and suitability. Crucially, such a compromise will have real ramifications for the act of writing, as we will see. While the choice of 
material for the writing implement may have been driven by the craftspeople responsible for producing them (perhaps different individuals from the end users?), the embodied and socially situated use of the implement will make it an active agent in practised writing. In other words, the material properties of the implement will contribute not only to the materiality of the inscribed object but also to its perception within its social setting, and to its value as an instantiation of the broader concept, or cognitive framework, of writing. In the interaction between the writer, the stylus and the clay document lies the indirect evidence for the stylus's shape, which we can at least begin to reconstruct by examining the surviving clay documents and the incisions and impressions in the clay that were produced as a result of that interaction. We will begin with an overview of the palaeographic characteristics of clay documents from the different writing traditions of the Bronze Age Aegean and Cyprus.

There are only a few clay tablets understood to contain Cretan Hieroglyphic inscriptions, but there are also other clay document types bearing writing including clay bars, crescents and cones. The signs are typically incised quite shallowly, although it is sometimes possible to observe deeper rounded shapes where a sharp rounded implement has sunk further into the clay. Where these round depressions are incorporated into the lines that make up a script sign (e.g., in Figure 3), they give the impression that the writing end of the stylus was itself pointed and round, and varying sizes of round depression are likely the result of a stylus with a tapering point (hence thicker the further the stylus is sunk into the clay). Artemis Karnava has identified the use of thicker styli for inscribing some Cretan Hieroglyphic clay inscriptions in the context of her study of scribal hands, especially in the Quartier Mu at Malia (Karnava [28] pp. 98-109, esp. 105).

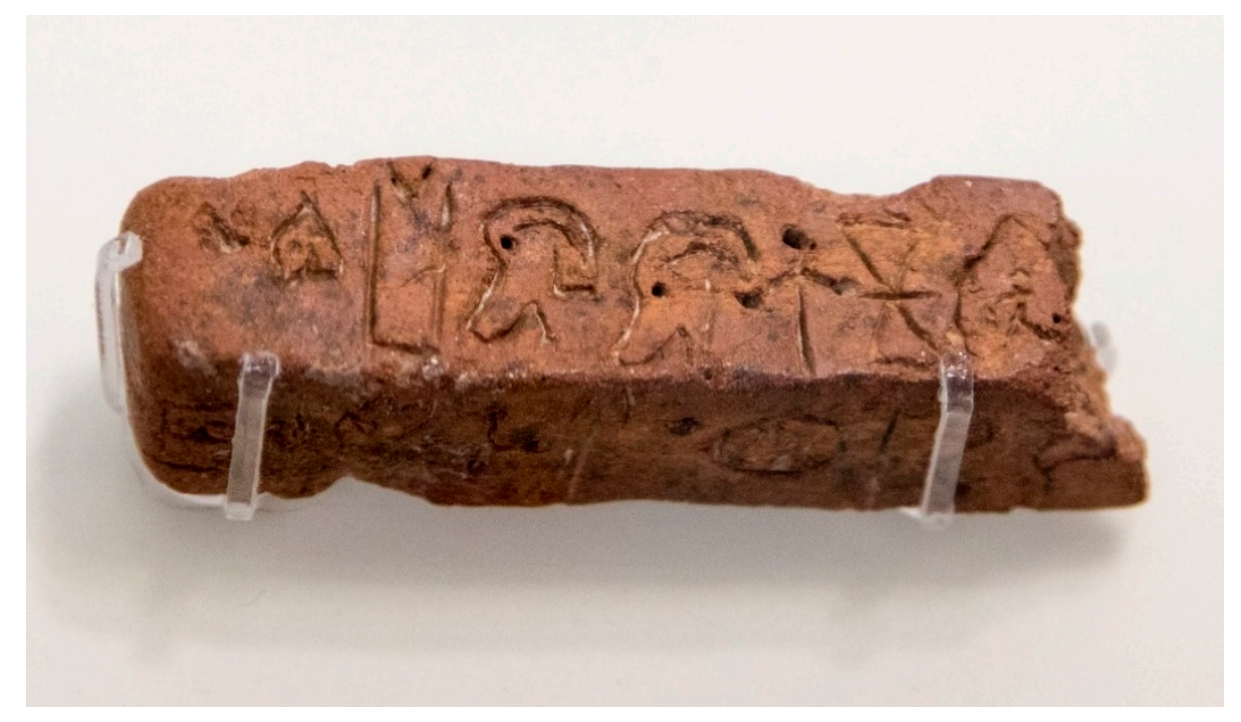

Figure 3. A four-sided Cretan Hieroglyphic clay bar. Image courtesy of Rupert Thompson.

Linear A presents us with far more examples of clay documents, many of which are tablets (on Linear A administration, see Schoep [29]). Again the signs are typically incised shallowly, with thin lines and evidence that the stylus featured a sharp, round tip (see for example the 'eyes' of the ma sign lying along the crack in the lower half of the tablet in Figure 4). This may put us in mind of John Chadwick's suggestion (though intended for Linear B) that 'writing was done with a needle-sharp stylus - perhaps a thorn mounted on some kind of holder-and then left to dry' (Chadwick [30] p. 18). I had the opportunity to attempt writing with an acacia thorn a few years ago, and found that its proportions made it perfect to incise signs accurately at the appropriate scale: the long, thin point was sharp and inflexible enough to produce incisions with very similar characteristics to those of real Linear A inscriptions (with thanks to my colleagues Torsten Meissner, who convened our Linear A self help group in 2017, and Sarah Finlayson, who provided the thorn; this thorn was large enough to hold quite comfortably in the hand without a mount or holder, and although acacia would not have been 
an available resource in Bronze Age Crete, any plant with reasonably large and sharp thorns could provide a very similar implement.). There seems to be little evidence here of the use of bladed styli, though, as we will see, the difference between impressions from rounded and bladed implements is not perhaps as obvious as you might assume. It is also important to bear in mind the diversity of Linear A writing practices, as employed by autonomous local administrations and used also outside of the strictly administrative sphere (for example on items associated with religious practice and with status display).

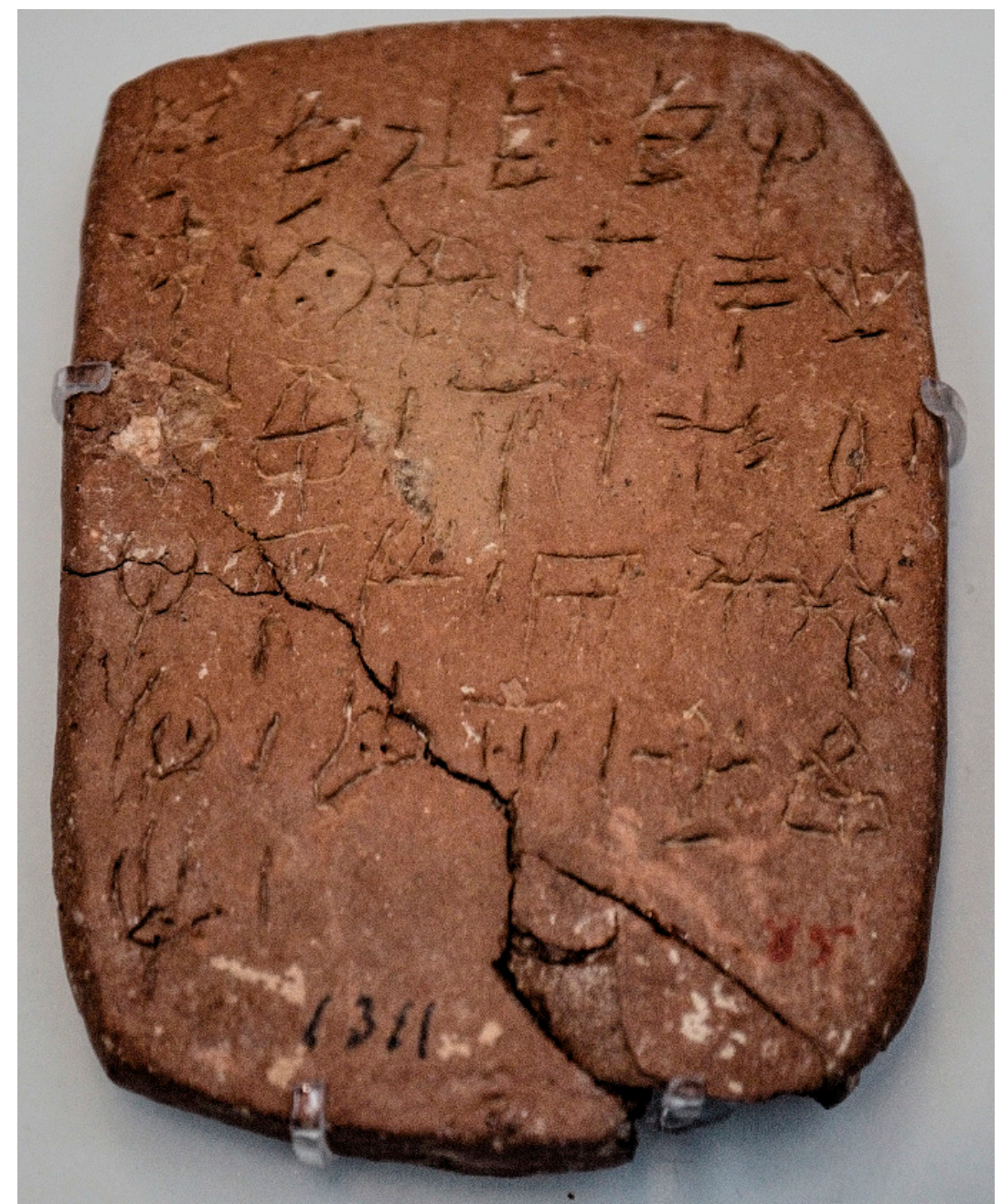

Figure 4. Linear A tablet. Image courtesy of Philip Boyes.

For Linear B, we are able to reach a much better appreciation of palaeographic features owing to the far larger corpus of surviving documents, and there is further potential to discern geographical and temporal variation given the spread of the evidence: c. 6000 documents found in Crete, both sides of the Peloponnese and Boeotia (plus a tablet fragment as far north as Thessaly). However, there is a great deal of work to do here, and the present article will only attempt to lay out some ideas and guiding principles that will hopefully pave the way for some interesting observations and inspiration for future research: detailed conclusions cannot safely be drawn except on the basis of extensive new palaeographic analysis of these documents. Since in the Argolid and in Thebes we have direct evidence for bladed styli, it makes sense to begin with tablets from these areas and to consider whether a stylus of this shape makes a distinctive impression.

The three signs in Figure 5 show some possible traits that might be associated with the use of a stylus with a flat blade approximately of the shape shown in Figure 1 above. The blade can glide 
easily through the clay, although for long straight lines it may be that the blade is angled to produce an impression of the right length instead of being drawn through the clay; this technique is discernible in the minimal displacement of clay around the stroke and its evenness from one end of the stroke to the other (e.g., the main vertical stroke in this example of $a_{2}$ ). Typically long straight strokes made with a blade will also be quite pointed at both ends (rather than terminating in a rounded shape). Curved lines, however, give more scope for discerning the dimensions of the implement. A large circular shape might be accomplished in two separate strokes as in this example of $k a$, where the width of the incision changes as each stroke is drawn. The reason for this must be that, although the writer does turn the stylus as they draw the line, they cannot easily do so in such a way that it keeps the width of the incision (i.e., the angle of the stylus blade with respect to the curve) constant. It is also the case that when drawing a tight curve in one stroke with a bladed instrument, the more pointed tip of the blade is the most effective part to turn, which means that the incision may be shallower than for less curved lines: we can see this in the loops of the $a_{2}$ sign here, especially the one on the right. The $t u$ in this example shows similar varying width of incision in its upper central curved line, and we also see that the sign's 'shoulders' have been formed with small separate horizontal strokes (rather than curving lines that continue the downward strokes of the $\mathrm{V}$ shape).

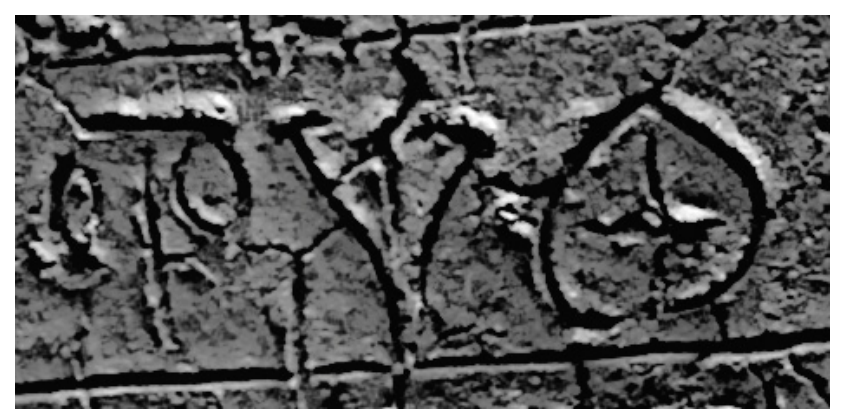

Figure 5. Three signs $\left(a_{2}, t u, k a\right)$ from a Linear B tablet from Mycenae. Digital drawing from a photograph, by the author.

It is also sometimes the case that horizontal strokes (especially shorter ones) will be wider than vertical strokes, which could be related again to the shape and dimensions of the blade. If it is held so that the flat dimension of the blade can form a thin vertical stroke, then it follows that-unless the writer turns the stylus by 90 degrees—a horizontal stroke will be made with the wider dimension of the blade. Clearly it is possible that a writer might hold, turn and manipulate the stylus in different ways, thus varying the degree to which the difference in width between vertical and horizontal stroke is noticeable.

The above examples serve to demonstrate that the relationship between author, implement and sign shape is not a straightforward case of the author envisaging a learnt sign shape and executing it with the implement-rather, the sign shape is influenced, enabled and constrained both by the author's understanding of the sign shape (and the broader cognitive system in which it exists) and by the material and shape of the implement and its interaction with the clay of the tablet. In other words, it is impossible to understand the act of writing, and the product of that act, without ascribing some agency to the stylus. The stylus further needs to be understood as having a complex relationship with administrative need and availability of materials and craft specialism, as the shape of the implement is a product of interaction and compromises between its intended use, the nature of the material used and the way it is fashioned into a writing implement. Materials such as bone or ivory would bring the advantages of being hard and durable, and being able to be drawn effectively through the surface of the clay, but would lend themselves far better to a shape that involves a flat sharp edge, since they are not well suited to a thin and sharp rounded point (which would also be more likely to break under pressure). While there may be some advantages here over the use of something like a thorn with a sharp, rounded point (e.g., in throwing up less clay, perhaps greater durability), the use of a bladed 
bone stylus would also impact on the execution of sign shapes, which could have wider implications for the script, from palaeographic variation to potential systemic changes. We will return to this point.

If a sharp, pointed stylus (something like a thorn) was used to inscribe Linear A clay documents, and a bladed stylus made of bone or another material was used to inscribe Linear B documents in at least the northern and eastern parts of the Mycenaean world, we might wonder what lies between (both chronologically and geographically) and how we get from one to the other. Was the thin, pointed implement used for Linear A ever used for Linear B? Or did the development of Linear B writing (accompanied by the distinctive aspects of Mycenaean bureaucratic practice) bring with it the use of a new type of stylus? We might expect to find the answer to such a question on Crete, which is by Occam's Razor the best candidate for the locus of the development of Linear B (though other locations have been suggested: see e.g., Palaima and Sikkenga [31]), and where speakers of Greek would have had the opportunity to observe Linear A accounting methods in practice. Palaeographic analysis of the Linear B documents from the Room of the Chariot Tablets at Knossos, assumed to be the earliest archive in Crete, and comparison with Linear A sign shapes, suggests 'a soft process of script adaptation' from Linear A to B (Salgarella [32] p. 89) where we might also expect some interaction between Minoan and Greek speakers in the development of bureaucratic practices in the Mycenaean palace (see also Salgarella [33]; see also Steele and Meissner [34]).

At Knossos, a site that has produced more than 4000 Linear B tablets, we find some considerable degree of variation in palaeographic features and it has not yet been possible to analyse every inscription from this perspective. However, from the sample consulted, some tablets show features that will be familiar from the above discussion, with for example thin (and shallow) vertical incisions accompanied by wider (and deeper) horizontal incisions (see Figure 6 for an example). Curved lines sometimes but not always vary in width, again perhaps pointing to the use of a bladed stylus. But there are differences too, particularly in the degree to which clay is displaced when incising signs. On the one hand, this could indicate some difference in the shape of the stylus, and practical experimentation suggests that a rounded implement (even a sharp one) will 'throw up' more clay as it moves through the surface of the clay; this ought to be minimised for a bladed stylus, both because the narrow cross section allows the blade to move through the clay more easily and because a straight blade can be impressed into the clay to make a straight line without drawing the blade through the clay at all, such that either method should involve minimal clay displacement. On the other hand, the size and shape of the implement is not our only material consideration here, and we must also bear in mind factors such as clay consistency and quality, and the dryness/wetness of the clay when it is inscribed. The shallowness of vertical lines in many tablets may suggest that, whatever the implement and whatever the other factors involved, there was a deliberate attempt to avoid displacement of too much clay when drawing longer strokes (as vertical ones generally are), whereas the shorter horizontal strokes were less of a concern.

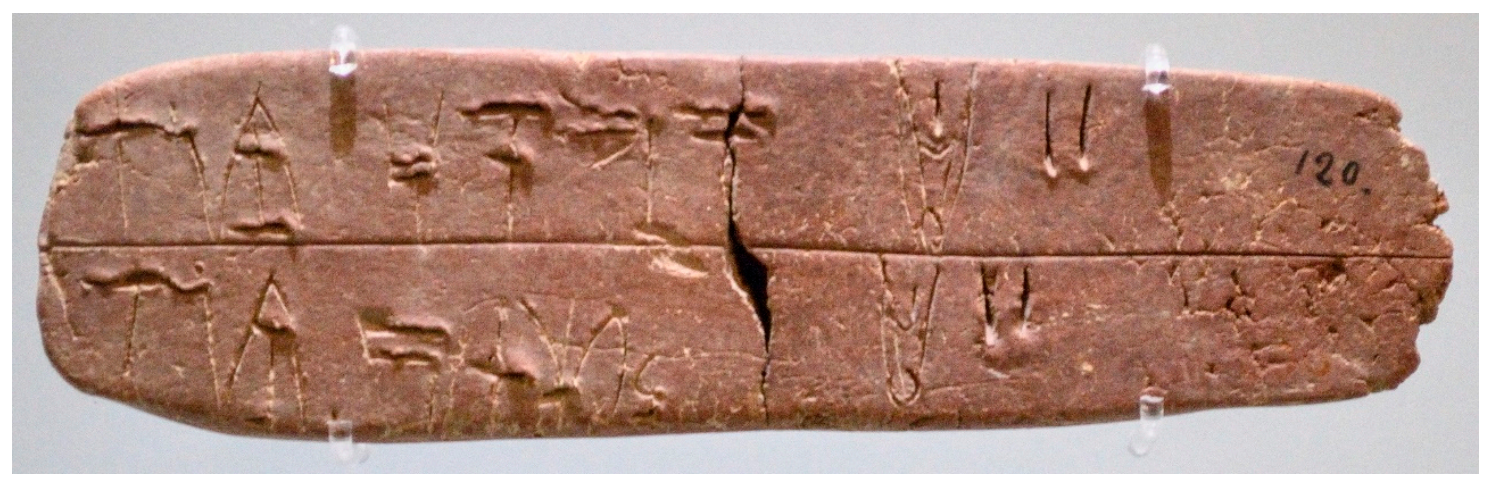

Figure 6. Linear B tablet from Knossos. Image courtesy of Philip Boyes. 
At Pylos we see some further palaeographical differences, in particular the 'boxier' appearance of signs in the tablets of some Pylian writers. Some tablets show limited evidence of the physical characteristics identified above as typical of the bladed stylus (e.g., the quite consistent stroke width in the tablet in Figure 7), but we should question whether that indicates beyond doubt that a stylus of different shape was used in such cases. Could it be, for example, that the method of holding and manipulating the stylus in the hand was responsible for the differences in appearance? Bronze Age writing in Cyprus can in fact offer an instructive parallel here.

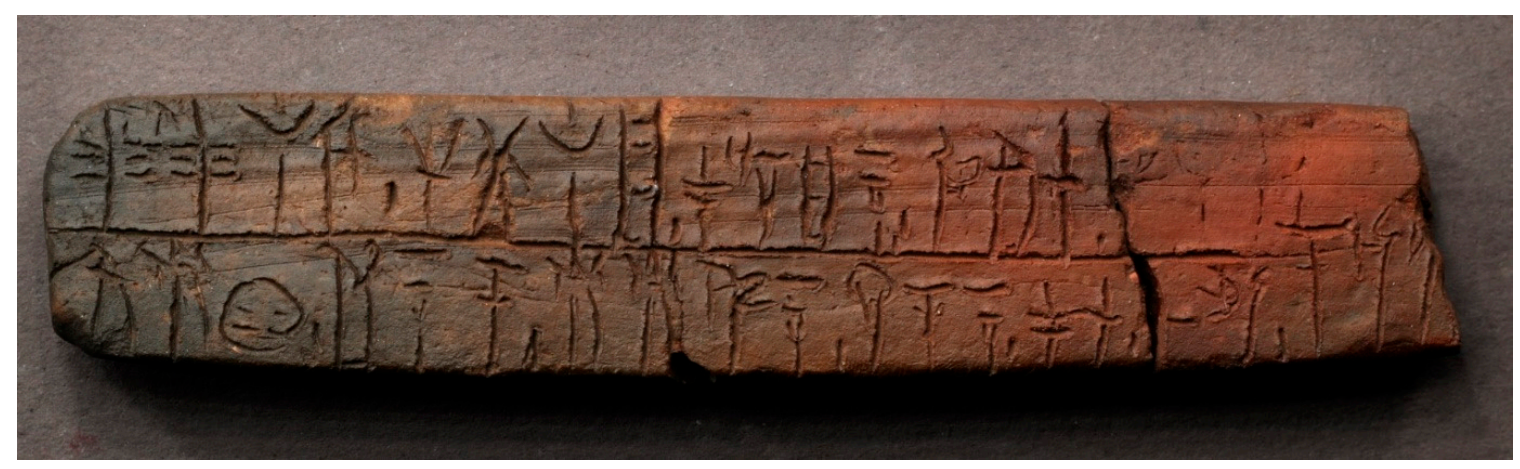

Figure 7. Linear B tablet from Pylos. Courtesy of the Department of Classics, University of Cincinnati.

Cyprus presents quite a different situation, as writing on clay looks far less standardised than we see in the Aegean, and the numbers of inscriptions (including clay documents) are by far weighted towards the well excavated site of Enkomi. Early scholarship on Cypro-Minoan writing acknowledged the importance of studying the material features of the documents in order to understand the way in which this degree of variation affected the very structure of the writing system (Daniel [35]). The diversity of surviving examples of Cypro-Minoan writing is itself problematic in this regard, and across the whole corpus it is likely that there was also considerable diversity in the type and shape of writing implement used (see the discussion in Ferrara [36] pp. 197-203, as well as Palaima [37] pp. 136-138 and 155), presumably including not only implements designed exclusively for writing (i.e., styli) but also other tools that may have been involved in craft production (e.g., in examples where writing is incorporated into the fabric or decoration of an object whose sole purpose is not to carry writing). Even the very small number of surviving clay tablets (found at Enkomi, Pyla-Kokkinokremos and Ras Shamra-Ugarit on the Syrian coast) show very considerable variation in their sizes, shapes and methods of inscription (see recently Steele [38] chapter 3 with references). The shape of the stylus used to inscribe most of these clay documents is relatively easy to reconstruct from the impressions in the clay that make up script signs (I would like to thank Martina Polig for showing me her 3D textured light scans of Cypro-Minoan inscriptions, which make it possible to measure the dimensions of a given impression, and so to calculate some of the dimensions of the stylus-bearing in mind some caveats, e.g., that it is more difficult to capture deeper impressions with this type of scanning, and that we have to account for the effect of the implement being moved in or through the clay). This is a rounded stylus, but not with a long, sharp point like that used for Linear A: instead it comes to a point after a very short taper, such that when impressed and angled in the clay it creates a distinctive 'teardrop' shape (see Figure 8). For the clay tablets, although the basic shape of the stylus with a short tapering point was apparently common, methods of holding it and drawing and/or impressing it in the clay could sometimes give quite distinct appearances to different groups of objects (see Steele and Boyes [27]). No object with the right proportions that I know of has been found in the archaeological record. Among the other inscribed clay documents such as the clay balls (see Figure 8 below, with clear 'teardrop' impressions), a stylus of similar shape was clearly used in many cases, although in others the point of the stylus may have been sharper and narrower. 

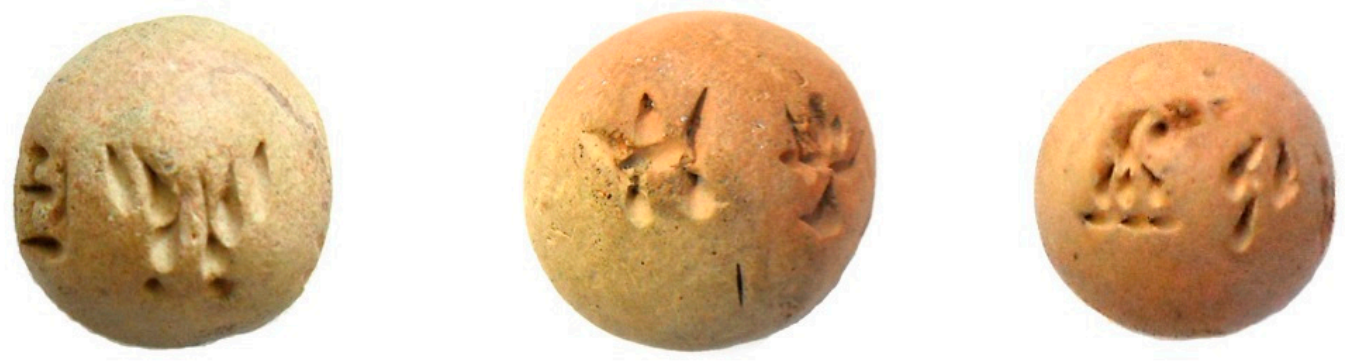

Figure 8. Cypro-Minoan clay balls. Image courtesy of Silvia Ferrara.

In the earliest phase of Cypro-Minoan writing, however, there is some evidence to suggest that a bladed implement might have been used to write clay documents at Enkomi. The earliest surviving clay tablet (16th-15th C BC, some hundred years before the Cypro-Minoan floruit: see Ferrara [36]) in particular bears impressions that include some of the characteristics identified above as characteristic of a bladed implement. Perhaps the giveaway is that the sign at the left end of the second line (clearly related to Linear A $k a$ ), which involves a circle with a cross in the middle, is formed in multiple jabs of a straight-edged stylus rather than drawn in the round (most obvious in the bottom-right of the sign: see Figure 9). This looks like an intriguing link with the Aegean, but it is not obvious how we should interpret it. Cypro-Minoan (and this tablet in particular) pre-dates Linear B and-as a system at least—has to be understood as a development from Linear A (see Valério [39] for a palaeographic discussion). Should we assume that the bladed stylus was an object associated with some sort of Cretan writing in the Minoan period? Or could it even be that ideas about stylus type move in the other direction, from Cyprus to Mycenaean Greece? Tempting as these questions may be, there is little evidence we can call on to try to resolve them-except perhaps a tentative connection between Bronze Age Cyprus and Tiryns, where an inscribed Cypro-Minoan clay ball and some blanks have been found (Vetters [40]) although they date to the postpalatial period and cannot speak for earlier literate connections. It also seems at the least possible that the use of bladed styli in the early stages of Cypro-Minoan writing had a significant effect on the development of sign shapes, which mostly look palaeographically very different from their Linear A counterparts. For example, the Linear-A-looking $k a$ sign (composed of a circle with a cross in the middle) in the earliest clay tablet seems to be a precursor to Cypro-Minoan sign 25, usually consisting of two sloping lines meeting at a point at the top, with a cross underneath. Valério sees this development as 'an increasing propensity to open the sign at its lower edge' ([39] p. 145), a trend that could plausibly be driven by the use of a bladed stylus, with which it is far more difficult to draw a smooth complete circle than with a rounded, narrowly pointed stylus.

Whatever the trajectory of changes in stylus type and usage in those earlier stages, we can at least be sure that the Aegean and Cyprus had divergent trends. The differences in writing practices prove illustrative if we look more closely at sign shapes (alongside writing system structure) in both areas, as can be seen from the initial discussion of the $k a$ sign above. Another instructive example is found in the $n a$ and to signs of the Aegean scripts. In Linear B (Figure 10), the essential difference between the signs $n a$ and to is that $n a$ has a gap below the upper horizontal line, while to has a tall vertical that extends through a lower horizontal line all the way up to the upper horizontal line. A na may sometimes look like a to but without the gap between the two horizontal lines, or it there may be some distinguishing features on the stem (e.g., a dotted stem or a curved shape at the top of the stem), and the lower horizontal line is not a compulsory feature. Meanwhile, in Cypro-Minoan (Figure 11) we find shapes that are similar to a simple $n a$ or to with two horizontal lines either with a gap between them or a vertical extending through them to the top; and at the same time we find a to where the vertical line has moved to one side of the sign, and can appear at an angle to the horizontal line at the top, while another variant has a horizontal line at the top with two angled lines extending down, often staggered. Miguel Valério has convincingly argued that in Cypro-Minoan, a sign that has a central vertical extending between the two horizontal lines should be understood as a na rather than 
a to, and sees the other shapes of to with its vertical at one side or with angled lines as attempts to distinguish between the two sign shapes ([41]). It is just a coincidence that this results in a shape that would in Linear B indisputably represent the syllable to having a completely different value $(n a)$ in Cypro-Minoan. The important point for our purposes is that these divergent features, which are systemic in that they involve differences in sign shape and value, are heavily entangled with the material properties of the clay documents being inscribed and the implements used to inscribe them. Whether making use of a rounded stylus with a sharp point or a bladed stylus, Linear B is being written at a larger scale with an implement that is capable of distinguishing between minute features. The development of bowed or dotted stems in the sign na may have something to do with making the sign distinctive from to, but, even so, the most simple form of na persists. By contrast, in Cyprus different strategies have been developed to distinguish $n a$ from to, and we can confidently link them with the problem of writing with a less sharp instrument, and often at a smaller scale (especially in the case of clay tablets). This is not a case of arbitrarily different choices in attempting to distinguish between potentially confusable signs-these are developments in the properties of the writing system that are deeply embedded in practice, and that are entangled with issues of document type and medium, material and shape of stylus and embodied action, all contributing to the practice (or we could say the cognitive architecture) of writing.

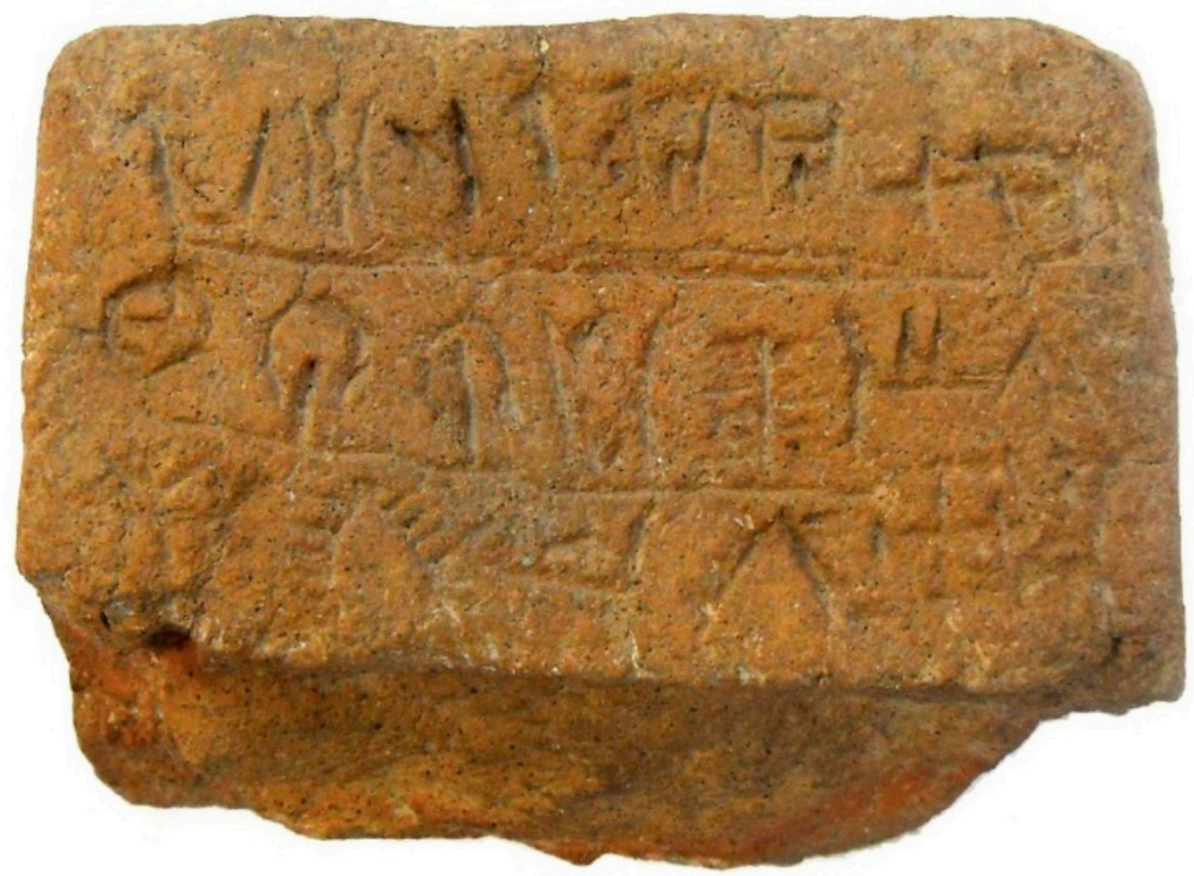

Figure 9. The earliest Cypro-Minoan clay tablet. Image courtesy of Silvia Ferrara.

The purpose of this section was to illustrate some of the central issues related to reconstructing stylus shapes. It was not intended as in any way exhaustive, and there remains a great deal of work to be done to survey, document and analyse the palaeographic features of documents in the Aegean linear scripts. Advanced digital imaging techniques (such as RTI—reflectance transformation imaging-and 3D scanning) have an important role to play because they give unprecedented scope to analyse minute palaeographic details, as pilot studies have already shown. The forthcoming publication of the Pylos corpus by an American team complete with RTI images of each inscription will be an impressive resource (I am grateful to Sharon Stocker, Cassandra Donnelly and Dimitri Nakassis for permission and help in accessing some of these RTI images) and there have also been smaller pilots involving RTI, including the Pa-i-to project (https://www.paitoproject.it/en/pa-i-to-project-2/) and the Ashmolean's online gallery (https://sirarthurevans.ashmus.ox.ac.uk/collection/linearb/images.html); a current doctoral project by Martina Polig (Ghent University / Cyprus Institute Nicosia) is using a 
different method, 3D textured light scanning, to approach Cypro-Minoan palaeography. The use of enhanced imaging techniques can make it possible to observe the direction and order of strokes in a given sign, for example, and to establish something of their relative depth and the proportions of the incision/impression, provided we develop secure analytical methods for interpreting the enhanced visual evidence, supplemented by other methods such as practical experimentation (see Greco and Flouda [42] p. 155). Such combined approaches have the potential to put us in a stronger position when interpreting the traces and impressions of writing implements in the material record.

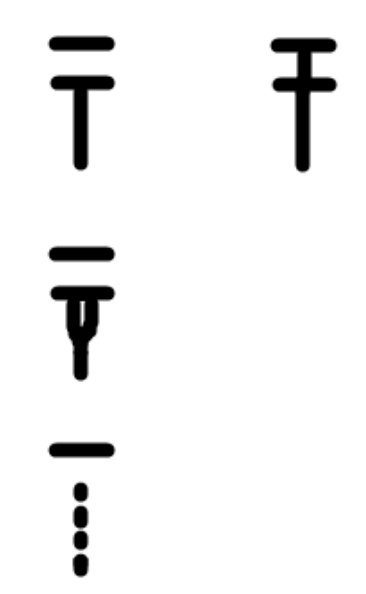

Figure 10. Shapes of $n a$ (left) and to (right) in Linear B.

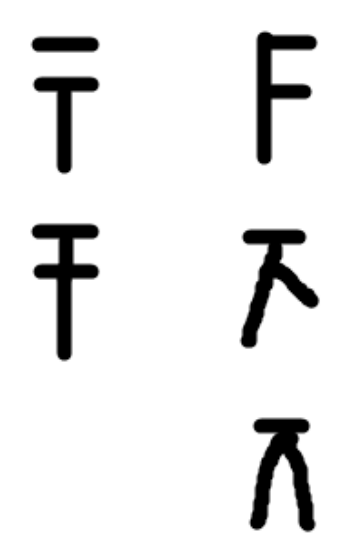

Figure 11. Shapes of $n a$ (left) and to (right) in Cypro-Minoan.

\section{Using the Stylus}

Now that we have considered the direct and indirect evidence for stylus types, it is important to conclude by turning some attention towards the users of the styli and the conditions in which they were writing. It is fair to say that we know very little about the authors behind the documents written in the Aegean linear scripts. They are anonymous in every sense, and unlike in the Near East, they never sign their documents or leave us their names. No term for a professional scribe is recorded. For Cretan Hieroglyphic, Linear A and Cypro-Minoan, only quite limited work has been done to identify individual writers, but Linear B is a considerable exception. Decades of research and the availability of thousands of deciphered documents have allowed a composite picture to be reconstructed, moving from the palaeographic identification of individual hands (Olivier [43], Palaima [44]) to studies of the bureaucratic interests of these individuals integrated with the physical distribution of the documents they wrote. In a couple of cases, it may even be possible to infer that a name mentioned in a tablet may belong to its author, most famously in the case of $p u_{2}-k e-q i-r i$ in PY Ta 711 (Hand 2). For the Mycenaean world we can confidently assume that we are dealing not with 
professional scribes in the sense of the Mesopotamian $d u b$-sar but with professional administrators for whom literacy happened to be a key aspect of their work (see Bennet [45]).

There must be many open questions as to the social context of stylus use and the interaction between writer and stylus. Was the choice of stylus type determined by the rigorous training that we know Linear B writers to have undergone? The very significant degree of standardisation in other aspects of writing practice (including tablet shape and layout, arrangement of text, script repertoire and sign shapes, orthography, etc.) strongly suggests that Mycenaean administrators were trained to a high degree (Duhoux [46]) and stylus use may have been a significant part of that - though we lack direct evidence such as the practice cuneiform texts known from Mesopotamia, which included exercises in forming wedges with the stylus. Could an individual writer make an individual choice about the stylus they used? Might two options have been available in some contexts, and the choice free to the writer? Might some styli have been better made than others (or made from more precious materials), and perhaps have been associated with prestige and relative status (factors which can also be assumed from the clear signs of hierarchical structures in administration with some writers having more wide-ranging administrative responsibility for example)? Were there different preferences in embodied practice, e.g., the way in which a writer held the stylus in the hand and positioned it in relation to the document? Or was posture also a heavily trained aspect of writing? The latter is a difficult question to approach in the absence of iconographic evidence like that found in the many depictions of scribes in Egyptian art, but the traces of this physical human-thing interaction are there to be studied in the surviving documents themselves.

We cannot at this point offer answers to all the above questions, nor should we try to, given the limitations of the evidence. But that does not mean that the questions may not in themselves be revealing, or that they cannot contribute to our interpretation of the surviving epigraphic record. One of the most intriguing avenues that this approach can take is to bring the issue of writing implements and practices into conversation with wider questions of the nature and spread of writing across the Bronze Age Aegean and Cyprus. The latter questions have typically been approached by adopting a writing systems perspective that places the Aegean linear scripts on a sort of family tree and views them in ancestor/descendant relationships with each other based on shared or divergent sign shapes and values. This is, to be sure, a very useful, tried and trusted way of studying the differences between the systems, and is comfortably grounded in structuralist and grapholinguistic approaches. But by approaching writing from a different angle, as a practice in the context of its social setting and material entanglements, we can find another way of looking at the relationships between these traditions. As we have seen, there are some important differences in stylus use that require explanation. When and why was the very sharp rounded implement used for Linear A abandoned? This must point specifically towards some change in attitudes towards the material aspects of writing practice, and should be viewed alongside other changes in documents shapes and types (see Tomas [47,48]). What were the origins of the bladed stylus (particularly if Greek speakers were, as usually assumed, illiterate before acquiring and adapting Linear A to make a new writing system and tradition), and where and how did it become a preferred implement for writing? When and how did the distinctively-shaped Cypriot rounded stylus with a short tapered point become popular in the writing of clay tablets and other document types? These are issues that relate to the spread of writing systems and writing practices around the Aegean and eastern Mediterranean, and with further research it may be hoped that a study of writing implements can help to elucidate how writing practices developed in different areas at different times, and how they 'moved' as sets of practices were adopted and adapted by new groups of people.

I have also aimed to illustrate that by taking a fresh theoretical approach, we can understand writing implements as more than an intermediate between the cognitive system (made up of the author's understanding and experience of writing as system and practice) and the end product (the inscription in its material and social context) of any given act of writing. What I hope is already 
clear from the present discussion is that the writing implements need to be viewed as active agents within the mesh of interconnected people, things and behaviour that coalesce in writing practices.

Funding: This research was conducted as part of the CREWS project, Contexts of and Relations between Early Writing Systems, which has received funding from the European Research Council (ERC) under the European Union's Horizon 2020 research and innovation programme (grant agreement No 677758).

Acknowledgments: I would like to thank: Philip Boyes for reading and commenting on this article; the anonymous reviewers for their very helpful suggestions; the community of Aegean scripts scholars based here in Cambridge for their very helpful collaboration and feedback; numerous other colleagues for sharing their work electronically during the Covid-19 pandemic, which otherwise made this article challenging to develop and write up.

Conflicts of Interest: The author declares no conflict of interest.

\section{References}

1. Balke, T.E.; Tsouparopoulou, C. (Eds.) Materiality of Writing in Early Mesopotamia; De Gruyter: Berlin/Heidelberg, Germany; Boston, MA, USA, 2016.

2. Hoogendijk, F.A.J.; van Gompel, S.M.T. (Eds.) The Materiality of Texts from Ancient Egypt: New Approaches to the Study of Textual Material from the Early Pharaonic to the Late Antique Period; BRILL: Leiden, The Netherlands; Boston, MA, USA, 2018.

3. Piquette, K.E.; Whitehouse, R.D. (Eds.) Writing as Material Practice: Substance, Surface and Medium; Ubiquity Press: London, UK, 2013.

4. $\quad$ Baines, J.; Bennet, J.; Houston, S. (Eds.) The Disappearance of Writing Systems: Perspectives on Literacy and Communication; Equinox Publishing Limited: London, UK, 2008.

5. Englehardt, J. (Ed.) Agency in Ancient Writing; University Press of Colorado: Boulder, CO, USA, 2012.

6. Boyes, P.J.; Steele, P.M.; Astoreca, N.E. Introduction. In The Social and Cultural Contexts of Historic Writing Practices; Boyes, P.J., Steele, P.M., Astoreca, N.E., Eds.; Oxbow Books: Oxford, UK, forthcoming.

7. Knappett, C. Thinking through Material Culture: An Interdisciplinary Perspective; University of Pennsylvania Press: Philadelphia, PA, USA, 2005.

8. Hodder, I. Entangled. An Archaeology of the Relationships between Humans and Things; Wiley-Blackwell: Chichester, UK, 2012.

9. Bourdieu, P. The Logic of Practice; Stanford University Press: Redwood City, CA, USA, 1990.

10. Whitley, J. The material entanglements of writing things down. In Theoretical Approaches to the Archaeology of Ancient Greece: Manipulating Material Culture; Nevett, L., Ed.; University of Michigan Press: Ann Arbor, MI, USA, 2017; pp. 71-103.

11. Flouda, G. Materiality of Minoan Writing: Modes of display and Perception. In Writing as Material Practice: Substance, Surface and Medium; Piquette, K.E., Whitehouse, R.D., Eds.; Ubiquity Press: London, UK, 2013; pp. 143-174.

12. Flouda, G. Materiality and script: Constructing a narrative on the Minoan inscribed axe from the Arkalochori cave. In SMEA Nuova Ser. 1; Edizioni Quasar: Rome, Italy, 2015; pp. 43-56. Available online: https: //www.researchgate.net/publication/284732861_Flouda_G_2015_Materiality_and_script_constructing_a_ narrative_on_the_Minoan_inscribed_axe_from_the_Arkalochori_cave_SMEA_Nuova_Serie_1_2015_43-56 (accessed on 1 June 2020).

13. Malafouris, L. The cognitive basis of material engagement: Where brain, body and culture conflate. In Rethinking Materiality: The Engagement of Mind with the Material World; DeMarrais, E., Gosden, C., Renfrew, C., Eds.; McDonald Institute for Archaeological Research: Cambridge, UK, 2004; pp. 53-62.

14. Malafouris, L. How Things Shape the Mind: A Theory of Material Engagement; The MIT Press: Cambridge, MA, USA, 2013.

15. Malafouris, L. Linear B as Distributed Cognition: Excavating a Mind Not Limited by the Skin. In Excavating the Mind: Cross-Sections through Culture, Cognition and Materiality; Johannsen, N., Jessen, M.D., Jensen, H.J., Eds.; Aarhus University Press: Aarhus, Denmark, 2012; pp. 69-84.

16. Overmann, K.A. Beyond writing: The development of literacy in the Ancient Near East. Camb. Archaeol. J. 2016, 26, 285-303. [CrossRef] 
17. Overmann, K.A. A Cognitive Archaeology of Writing: Concepts, Models, Goals. In The Social and Cultural Contexts of Historic Writing Practices; Boyes, P.J., Steele, P.M., Astoreca, N.E., Eds.; Oxbow Books: Oxford, UK, forthcoming.

18. Petrakis, V. Reconstructing the matrix of the 'Mycenaean' literate administrations. In Understanding Relations Between Scripts: The Aegean Writing Systems; Steele, P.M., Ed.; Oxbow Books: Oxford, UK, 2017; pp. 57-68.

19. Tomas, H. Linear B script and Linear B administrative practice: Different patterns in their development. In Understanding Relations between Scripts: The Aegean Writing Systems; Steele, P.M., Ed.; Oxbow Books: Oxford, UK, 2017; pp. 57-68.

20. Palaima, T.G. Scribes, scribal hands and palaeography. In A Companion to Linear B. Mycenaean Texts and their World, Volume 2; Duhoux, Y., Davies, A.M., Eds.; Peeters: Louvain-la-Neuve, Belgium; Walpole, MA, USA, 2011; pp. 33-136.

21. Cammarosano, M. The cuneiform stylus. Mesopotamia 2014, 49, 53-90.

22. Godart, L. Autour des textes en linéaire B de Tirynthe. Ausgrabungen in Tiryns 1982/83. In Archäologischer Anzeiger 1988; De Gruyter: Berlin, Germany; pp. 245-252.

23. Olivier, J.-P.; Melena, J.L.; Piteros, C. Les inscriptions en linéaire B des nodules de Thèbes (1982): La fouille, les documents, les possibilités d'interprétation. Bull. Corresp. Hellénique 1990, 114.1, 101-184. [CrossRef]

24. Palaiologou, H. Late Helladic IIIC cremation burials at Chania of Mycenae. In Brandbestattungen von der Mittleren Donau bis zur Ägäis Zwischen 1300 und 750 v. Chr Akten des Internationalen Symposiums an der Österreichischen Akademie der Wissenschaften in Wien, 11-12 Februar 2010; Lochner, A., Ruppenstein, F., Eds.; Austrian Academy of Sciences Press: Vienna, Austria, 2013; pp. 249-279.

25. Smith, J.S. Bone Weaving Tools of the Late Bronze Age. In Contributions to the Archaeology and History of the Bronze and Iron Ages of the East Mediterranean. Studies in Honour of P. Åström; Fischer, P.M., Ed.; Österreichischen Archäologischen Institutes: Vienna, Austria, 2001; pp. 83-90.

26. Pappasavvas, G. Writing on Cyprus: Some Silent Witnesses; RDAC, 2003; pp. 79-94. Available online: http://gnosis.library.ucy.ac.cy/handle/7/50625 (accessed on 2 June 2020).

27. Bultrighini, I.; Anglicker, E.M. (Eds.) Steele and Boyes. A comparative approach to methods of inscribing clay tablets: Interaction and innovation in Cyprus and Ugarit. In Current Approaches to the Materiality of Texts in Greco-Roman Antiquity. Available online: https: //www.academia.edu/33207201/Current_Approaches_to_the_Materiality_of_Texts_in_Greco_Roman_ Antiquity_Colloquium_session_at_the_119th_AIA_SCS_Annual_Meeting_in_Boston_4_7_January_2018 (accessed on 1 June 2020).

28. Karnava, A. The Cretan Hieroglyphic Script of the Second Millennium BC: Description, Analysis, Function and Decipherment Perspectives. Unpublished Ph.D. Thesis, Université Libre de Bruxelles, Brussels, Belgium, 2000.

29. Schoep, I. The Administration of Neoplatial Crete: A Critical Assessment of the Linear A Tablets and Their Role in the Administrative Process; Ediciones Universidad de Salamanca: Salamanca, Spain, 2002.

30. Chadwick, J. The Mycenaean World; Cambridge University Press: Cambridge, UK, 1976.

31. Palaima, T.G.; Sikkenga, E. Linear A > Linear B. In Meletemata. Studies in Aegean Archaeology Presented to Malcolm H. Wiener as He Enters His 65th Year (Aegaeum 20); Betancourt, P.P., Karageorghis, V., Laffineur, R., Eds.; Aegaeum: Liège, Belgium; Austin, Belgium, 1999; pp. 599-608.

32. Salgarella, E. Drawing lines: The palaeography of Linear A and Linear B. Kadmos 2019, 58, 61-92.

33. Salgarella, E. Aegean Linear Script(s). Rethinking the Relationship between Linear A and Linear B; Cambridge University Press: Cambridge, UK, 2020.

34. Steele, P.M.; Meissner, T. From Linear B to Linear A: The problem of the backward projection of sound values. In Understanding Relations between Scripts: The Aegean Writing Systems; Steele, P.M., Ed.; Oxbow Books: Oxford, UK, 2017; pp. 93-110.

35. Daniel, J.F. Prolegomena to the Cypro-Minoan Script. AJA 1941, 45.2, 249-282. [CrossRef]

36. Ferrara, S. Cypro-Minoan Inscriptions. Volume 1: Analysis. Volume 2: Corpus; Oxford University Press: Oxford, UK, 2012.

37. Palaima, T.G. Cypro-Minoan Scripts: Problems of Historical Context. In Problems in Decipherment, BCILL 49; Duhoux, Y., Palaima, T.G., Bennet, J., Eds.; Peeters Publishers: Louvain-la-Neuve, Belgium, 1989; pp. 121-187.

38. Steele, P.M. Writing and Society in Ancient Cyprus; Cambridge University Press: Cambridge, UK, 2018.

39. Valério, M. Script comparison in the investigation of Cypro-Minoan. In Understanding Relations between Scripts: The Aegean Writing Systems; Steele, P.M., Ed.; Oxbow Books: Oxford, UK, 2017; pp. 127-221. 
40. Vetters, M. A clay ball with a Cypro-Minoan inscription from Tiryns. Archäologischer Anz. 2011, 2, 1-49.

41. Valério, M. Problems of Cypro-Minoan palaeography: The case of sign shapes 08, 13 and 78. Kadmos 2013, 52.1, 111-134.

42. Greco, A.; Flouda, G. The Linear B Pa-i-to Epigraphic Project. Annivario della Scuola archeologica di Atene e delle Missioni italiane in Oriente. Annivario Della 2017, 95, 143-160.

43. Olivier, J.-P. Les Scribes de Cnossos: Essai de Classement des Archives d'un Palais Mycénien; Edizioni dell'Ateneo: Rome, Italy, 1967.

44. Palaima, T.G. The Scribes of Pylos; Edizioni Dell' Ateneo: Rome, Italy, 1988.

45. Bennet, J. Agency and Bureaucracy: Thoughts on the Nature and Extent of Administration in Bronze Age Pylos. In Economy and Politics in the Mycenaean Palace States. Proceedings of a Conference Held on 1-3 July 1999 in the Faculty of Classics, Cambridge; Voutsaki, S., Killen, J., Eds.; Cambridge Philological Society: Cambridge, UK, 2001; pp. 25-37.

46. Duhoux, Y. How were the Mycenaean scribes taught? In Proceedings of the International Colloquium "The Inner Workings of the Mycenaean Bureaucracy", University of Kent, Canterbury, 19-21 September 2008, Pasiphae 5; Kyriakidis, E., Ed.; Fabrizio Serra editore: Pisa, Italy; Rome, Italy, 2011; pp. 95-118.

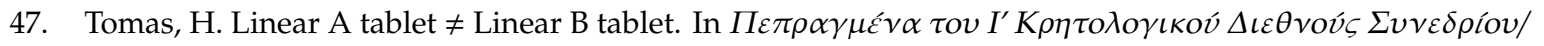
Proceedings of the 10th Cretological Conference, Chania, 1-8 October 2006, Vol. A1; Andreadaki-Vlazaki, M., Papadopoulou, E., Eds.; Literary Society “Chryssostomos”: Chania, Greece, 2011; pp. 331-343.

48. Tomas, H. Linear A scribes and their writing styles. In The Inner Workings of Mycenaean Bureaucracy (Pasiphae V); Kyriakidis, E., Ed.; Fabrizio Serra editore: Pisa, Italy; Rome, Italy, 2011; pp. 35-58.

Publisher's Note: MDPI stays neutral with regard to jurisdictional claims in published maps and institutional affiliations. 